\title{
Reações expansivas deletérias no concreto
}

\author{
NICOLE PAGAN HASPARYK - DOUTORA \\ Eletrobras Furnas \\ ORCID: https://orcid.org/0000-0001-7576-2681
}

\author{
SELMO CHAPIRA KUPERMAN - DoUTOR \\ DeseK \\ ORCID: https://orcid.org/0000-0003-4186-2216
}

\begin{abstract}
RESUMO
ESSE TRABALHO TRAZ INFORMAÇÕES SOBRE OS PRINCIPAIS TIPOS DE REAÇÕES EXPANSIVAS QUE PODEM ACOMETER AS ESTRUTURAS DE CONCRETO E LEVÁ-LAS À DETERIORAÇÃO. O OBJETIVO PRINCIPAL É ALERTAR A TODOS OS PROFISSIONAIS ENVOLVIDOS NO PROCESSO DE CONSTRUÇÃO DE UMA OBRA CIVIL QUE CONTENHA O MATERIAL CONCRETO QUANTO AOS SÉRIOS RISCOS DESSAS MANIFESTAÇÕES PATOLÓGICAS, DE FORMA A EVITAR DANOS E REFLEXOS NEGATIVOS NO DESEMPENHO E DURABILIDADE DE SUAS ESTRUTURAS.
\end{abstract}

OS TIPOS MAIS COMUNS DE REAÇÕES EXPANSIVAS SÃO ABORDADOS, ALÉM DA APRESENTAÇÃO DE ALGUNS CASOS REAIS DE DETERIORAÇÃO. SÃO CONTIDAS INFORMAÇÕES RELEVANTES PARA O ENTENDIMENTO DO MEIO TÉCNICO DA SEVERIDADE DOS FENÔMENOS E SUAS GRAVES CONSEQUÊNCIAS. AlgunS DOS CUIDADOS NECESSÁRIOS SÃO INDICADOS NESTE TRABALHO, DE FORMA A REDUZIR OS RISCOS DESSAS OCORRÊNCIAS NO CONCRETO, QUE NÃO PODEM SER NEGLIGENCIADOS.

Palavras-chave: concreto, reações expansivas, RAA, DEF, sulfetos.

\section{INTRODUÇÃO}

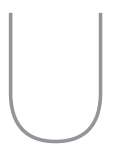

m grande número de estruturas tem apresentado deterioração em elementos de concreto, com quadros intensos de fissuração e prejuízos à qualidade do concreto e ao desempenho das suas estruturas, com reflexos na durabilidade e vida útil. São vários os diagnósticos decorrentes de reações expansivas que vêm acometendo as estruturas, muitas delas por ataques individuais como a RAA (reação álcali-agregado) e os ataques por sulfatos (conhecidos internacionalmente por ISA - Internal Sulfate Attack e ESA - External Sulfate Attack), outras sofrendo ataques combinados, a exemplo da RAA+DEF (onde DEF significa Delayed Ettringite Formation, ou formação da etringita tardia).

Além das estruturas de concreto especiais, em empreendimentos de grande porte, como as de usinas de geração de energia (hidrelétricas, eó- licas, térmicas, nucleares), barragens e pontes, são confirmados variados casos de deterioração em blocos de fundação de edificações, dormentes, e outros elementos de concreto.

O conhecimento dos variados tipos de fenômenos deletérios que podem deteriorar o concreto se faz necessário para que medidas preventivas possam ser adotadas na fase de concepção do projeto. Um controle tecnológico adequado no que diz respeito à caracterização e ao controle dos materiais a serem empregados é de suma importância na fase que antecede a execução da obra, bem como durante a obra, de forma a acompanhar o avanço da construção. Algumas medidas já estão contidas na normalização técnica nacional.

A divulgação dos casos de deterioração é de extrema importância, pois auxilia o entendimento dos fenômenos e o meIhor conhecimento do comportamento do concreto ao longo do tempo, fazendo com que intervenções, medidas mitigadoras e atenuantes das expansões, como reparos e/ou reforços, sejam aplicadas cautelosamente. Embora as medidas terapêuticas sejam paliativas, faz-se necessário o conhecimento adequado por parte dos engenheiros e a conscientização do meio técnico quanto à gravidade do problema, de forma a optarem pela prevenção, que é muito mais efetiva. Ainda, o monitoramento das estruturas, quando do diagnóstico de reações expansivas, é fundamental para a predição da evolução dos fenômenos e tomadas de decisão.

Diante do exposto, este trabalho tem o intuito de trazer para o meio técnico informações relevantes sobre as reações expansivas, como exemplo de casos, consequências e cuidados necessários de forma a evitar essas ocorrências no concreto.

\section{REAÇÕES EXPANSIVAS}

O concreto pode sofrer deterioração ao longo de sua vida útil, 
sendo que o tipo de ocorrência e as consequências vão depender da causa do ataque. São variados os processos de deterioração existentes, destacando-se os químicos, físico-mecânicos, biológicos e eletroquímicos.

As reações ditas "expansivas" envolvem processos químicos que ocorrem no concreto, levando-o à deterioração, dependendo do tipo de agente causador, dos materiais envolvidos, do tipo de concreto, da dimensão do elemento estrutural e do ambiente de exposição. Esses tipos de manifestações patológicas podem ocasionar graves danos às variadas estruturas de concreto e aos elementos estruturais ao longo da vida útil.

Dentre os vários tipos de reações químicas expansivas que podem afetar a qualidade e durabilidade do concreto, destacam-se as reações alcalinas, como a reação álcali-sílica (RAS) e as reações envolvendo os sulfatos. Neste trabalho serão abordadas as reações mais comuns e que têm afetado muitas das estruturas de concreto, sem a pretensão de abranger todas as situações. Outros tipos de reações químicas deletérias também podem ocorrer.

\section{I RAA}

A reação álcali-agregado (RAA), e mais especificamente o tipo álcali-sílica (RAS), ocorre a partir de uma interação química entre alguns minerais silicosos considerados reativos, contidos nos agregados (miúdos e graúdos), e os hidróxidos alcalinos presentes na solução dos poros do concreto (envolvendo o elemento químico potássio, K, e o sódio, $\mathrm{Na}$ ), cuja origem é geralmente o cimento. Os álcalis podem ser fornecidos também a partir de outras fontes, como as adições minerais, o próprio agregado, a água, entre outras. Na presença de umidade, quando dessa interação química, são formados no interior do concreto produtos com caráter expansivo, que, dependendo da intensidade, levam o concreto à fissuração e deterioração.

A Figura 1 registra os fatores condicionantes da RAA.

\subsection{Ataque por sulfatos}

$\bigcirc$ ataque por sulfatos (sais relativos ao ânion sulfato $\mathrm{SO}_{4}^{-2}$ ) é uma ocorrência que também traz fissuração e graves reflexos na integridade do concreto. São várias as fontes potenciais de sulfatos, podendo ser externas ou internas, trazendo as denominações de ataque externo por sulfatos (ESA External Sulfate Attack) e de ataque interno por sulfatos (ISA - Internal Sulfate Attack), conforme a seguir:

> Fontes externas: águas residuais industriais; águas do subsolo; esgoto; água do mar; chuva ácida; solos e águas agrícolas contaminadas por fertilizantes;

> Fontes internas: cimento, adições, água de amassamento e agregados. Quando o cimento representa a

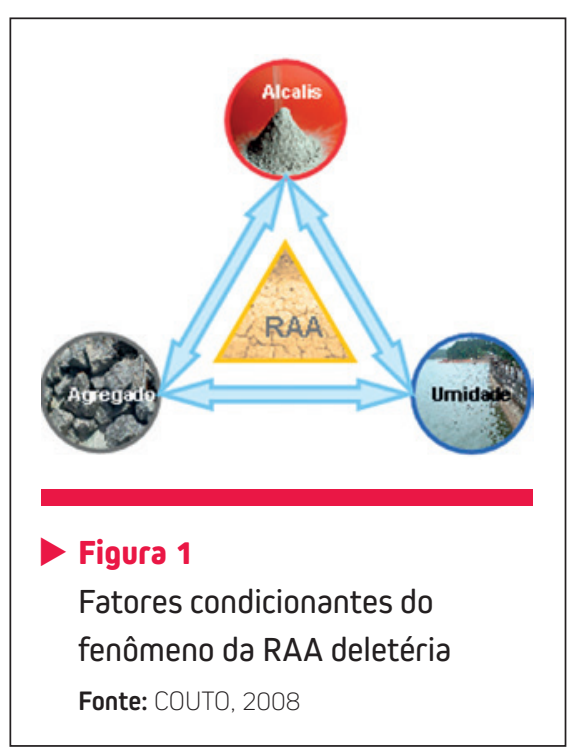

principal fonte interna de sulfatos, uma das causas pode estar relacionada a teores inadequados de sulfatagem (regulador de pega) no processo de sua produção. Considerando que esse controle foi apropriado, duas outras possibilidades estão relacionadas à temperatura, ocasionando a formação de etringita tardia (DEF - Delayed Ettringite Formation), a saber:

> Elevado calor de hidratação decorrente das reações exotérmicas do cimento, trazendo elevadas temperaturas ao concreto nas primeiras idades;

Curas térmicas inadequadas, a altas temperaturas.

Nas duas situações indicadas relacionadas à temperatura, ocorre alteração química interna no concreto, modificando o processo de hidratação normal do cimento. O produto de hidratação denominado etringita primária (trissulfoaluminato de cálcio hidratado) se torna instável ou não se forma nas idades iniciais da forma como era esperado. Assim, sulfatos ficarão disponíveis na solução dos poros do concreto, adsorvidos no C-S-H ou mesmo na forma de outros compostos, como é o caso do monossulfoaluminato de cálcio hidratado, por exemplo. Após o resfriamento do concreto, o meio volta a trazer estabilidade a esse composto etringita ao longo do tempo, sendo que os íons sulfatos disponíveis passam a reagir quimicamente para formá-la, quando do concreto já no estado endurecido, ocupando espaços, gerando tensões internas e expansões. Essas novas formações (muitas vezes chamadas de neoformações de etringita) trazem fissurações em nível micro e macroestrutural, deteriorando o concreto. Esse fenômeno é conhecido por DEF. 


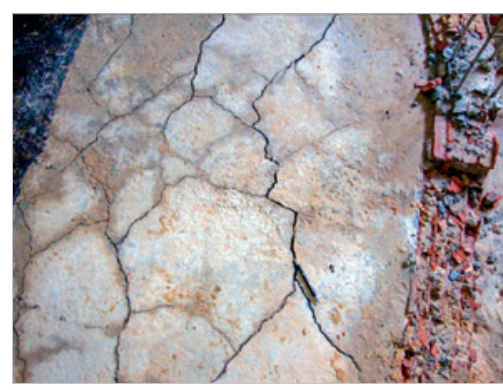

\section{Figura 2}

Detalhe de fissuração mapeada em bloco de fundação de prédio no Brasil causada por DEF

Fonte: Selmo C. Kuperman

No que diz respeito à temperatura a partir da qual esse fenômeno ocorre, ainda não existe um consenso, porém já existem relatos de ser acima de $60-65^{\circ} \mathrm{C}$.

Uma terceira possibilidade de ataque interno por sulfatos envolve o teor de álcalis do sistema. Nesse caso, e mesmo em temperaturas mais baixas, a presença expressiva de álcalis dissolve a etringita primária, e os sulfatos ficam também disponíveis na solução dos poros ou mesmo adsorvidos na estrutura do C-S-H.

No caso de a fonte interna ser o agregado, vários componentes contidos nesses também podem liberar esses íons e disponibilizá-los ao longo do tempo para uma interação química com a pasta de cimento e geração de produtos expansivos e deletérios, como a etringita secundária e a gipsita, por exemplo, entre outros compostos.

Alguns exemplos de fontes no agregado são:

> Sulfatos de cálcio e sulfatos de sódio;

> Minerais do tipo sulfetos, como a pirrotita, pirita, calcopirita, marcassita.

Quando a fonte direta são os sulfa- tos, o processo químico é bem semeIhante ao mencionado anteriormente, ou seja, os íons ficam disponíveis na solução dos poros do concreto para interagirem com a pasta de cimento e formar os produtos citados.

Já, com a presença de sulfetos (minerais contendo enxofre e metais, em especial o ferro) nos agregados, o processo é um pouco mais complexo do que um ataque por sulfatos tradicional. Inicialmente, os sulfetos (na presença de água e oxigênio) se oxidam, liberando enxofre e ferro para o meio. Assim, produzem tanto íons sulfatos quanto produtos secundários oriundos do seu próprio processo de oxidação, como os hidróxidos e óxidos ferrosos, além de sulfatos de ferro. Alguns desses compostos à base de ferro também podem ser expansivos e deletérios. Ainda, durante esse processo de alteração do enxofre, pode ocorrer a sua conversão para ácido sulfúrico, intensificando a deterioração no concreto. A instabilidade dos sulfetos é acelera- da pela alcalinidade do meio e $\mathrm{pH}$ acima de 10.

\subsection{Ataques combinados}

Quando do ataque combinado, o que ocorre é simplesmente uma associação de duas ou mais causas relatadas anteriormente. Geralmente, os ataques conjugados são atribuídos a uma interação entre a RAA e o ISA. No caso do ISA, seja com o cimento ou com o agregado, ou mesmo com ambos como fontes. Porém, os ataques mais comuns e relatados no meio técnico são aqueles envolvendo especificamente a RAS e a DEF. O nível e deterioração que um ataque conjugado pode atingir é tão elevado a ponto de trazer severas consequências em um curto prazo de tempo (menos de 1 ano).

\section{EXEMPLOS DE CASOS}

Alguns exemplos de casos de estruturas acometidas pela DEF são registrados a seguir.

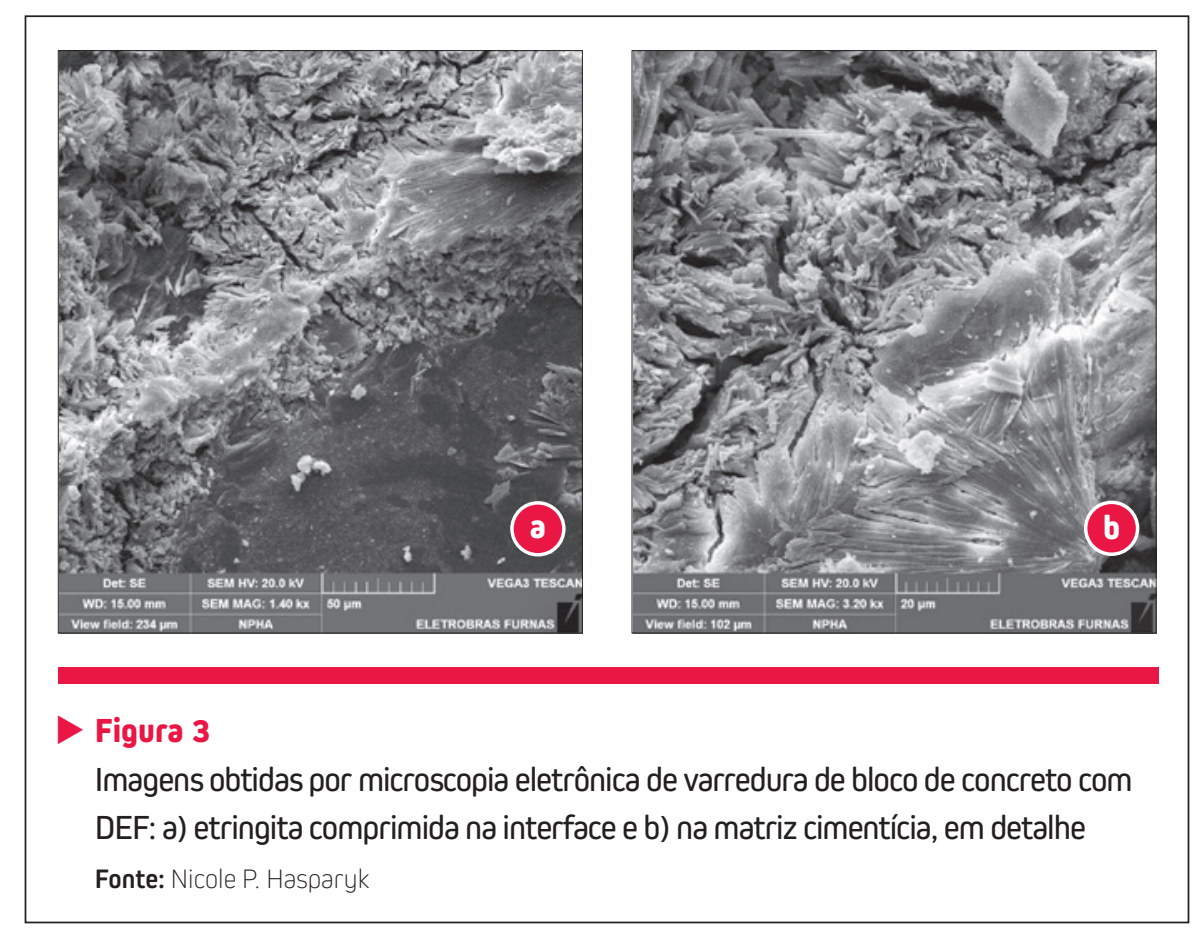




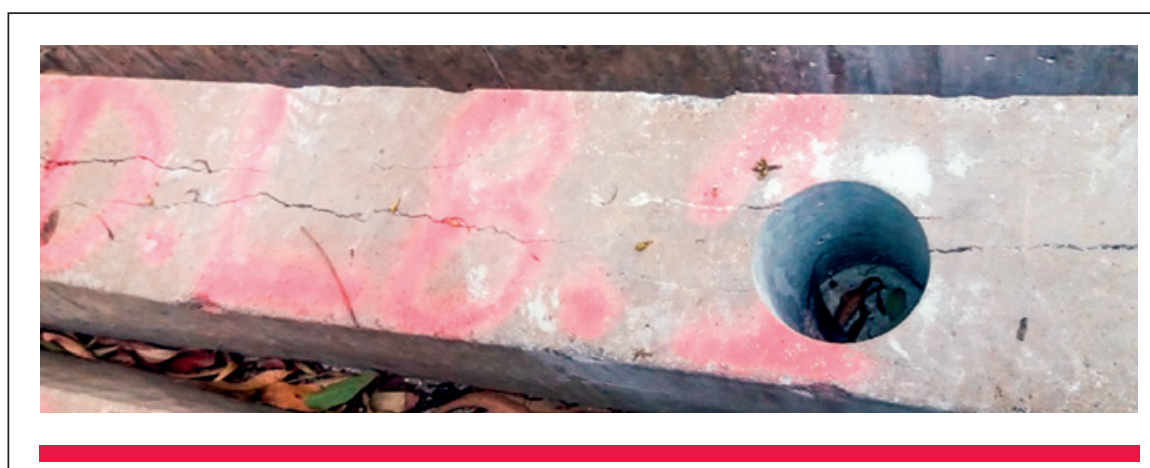

- Figura 4

Detalhe de dormente com alta incidência de fissuração e local de extração de testemunho de concreto para estudos em laboratório - ataque combinado da DEF e RAS

Fonte: Selmo C. Kuperman

Na Figura 2, por exemplo, pode ser observado um intenso quadro fissuratório pela ocorrência da DEF em bloco de fundação de edificação, registrando a gravidade do problema. Nesse caso, a causa foi a excessiva geração de calor a partir das reações de hidratação do cimento, sem os cuidados devidos durante a produção e lançamento do concreto.

No âmbito do diagnóstico da DEF em bloco de concreto com cer-

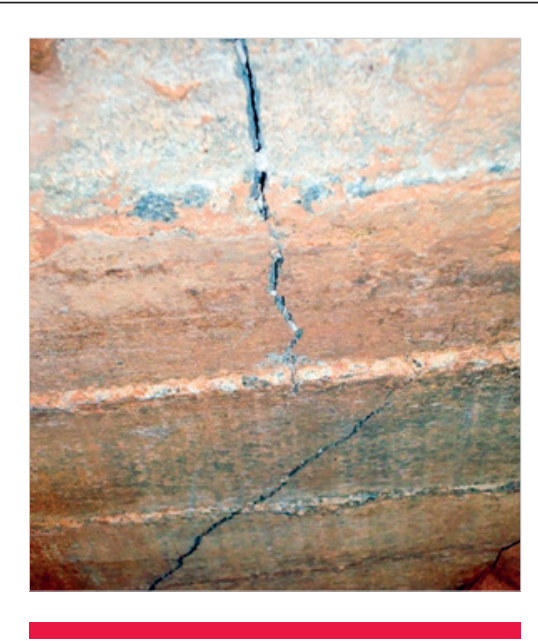

\section{Figura 5}

Fissuração em lateral de bloco de concreto

Fonte: Hasparyk et al. (2016) ca de 2 anos de idade, análises em testemunhos de concreto extraídos foram efetuadas por microscópio eletrônico de varredura e espectrometria por energia dispersiva de raios $X$ (MEV/EDS). As Figuras 3a e 3b representam micrografias obtidas a partir de estudos microestruturais dos testemunhos de concreto. O bloco de concreto foi dosado com consumo de $500 \mathrm{~kg} / \mathrm{m}^{3}$ de cimento do tipo CP V-ARI. A temperatura de pico nesse bloco foi de $101^{\circ} \mathrm{C}$ na região central, em decorrência do calor excessivo gerado pela hidratação do cimento, em virtude da não refrigeração e das características do cimento.

Esse tipo de ocorrência (DEF) tem também acometido peças pré-moldadas, além de barragens. Em dormentes de ferrovias, por exemplo, a deterioração do concreto vem sendo diagnosticada de forma expressiva. Para intensificar ainda mais os danos, muitos desses elementos vem sendo acometidos pela DEF em associação à RAS (ataque conjugado). Na Figura 4, encontra-se registrado um desses casos.

No Brasil, os ataques conjugados (DEF+RAA) têm sido diagnosticados de forma recorrente em variadas estruturas de concreto, e não apenas em elementos pré-moldados, destacando blocos de fundações e barragens (Figuras 5 e 6). Em inspeções de barragem brasileira, por exemplo, notou-se intenso quadro fissuratório após 50 anos de serviço, acompanhado de movimentação das estruturas do vertedouro. Para o correto diagnóstico em laboratório, testemunhos de concreto foram extraídos, seguido da confirmação do ataque conjugado. Entretanto, pela ausência de um sistema de instrumentação instalado nas estruturas, não foi possível confirmar a evolução das reações expansivas e prever o comportamento futuro.

Nas Figuras $7 \mathrm{a}$ e 7b, encontram-se alguns dos registros feitos durante a etapa de diagnóstico por MEV/EDS das manifestações patológicas em testemunhos de concreto de barragens brasileiras.

No caso da RAA, além de um quadro fissuratório característico, que, em geral, ocorre com fissuras mapeadas, fissuras orientadas em relação à

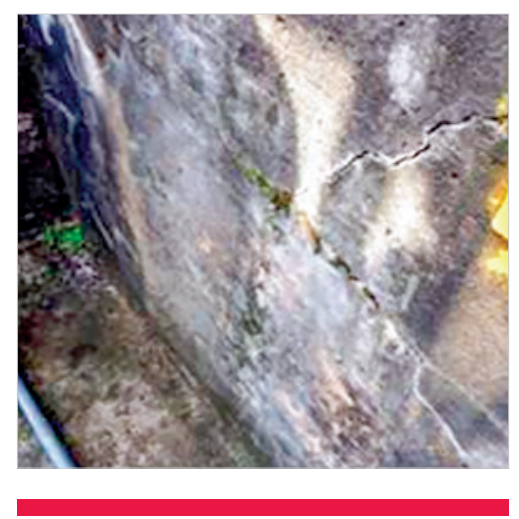

\section{Figura 6}

Fissuras por DEF e RAS em estrutura de concreto em vertedouro de UHE

Fonte: Selmo C. Kuperman 


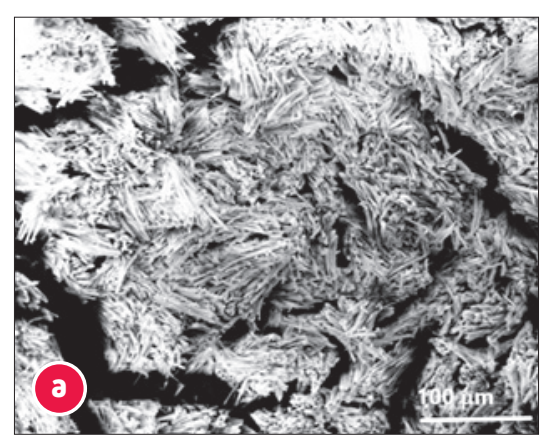

Etringita deletéria formada no interior do concreto

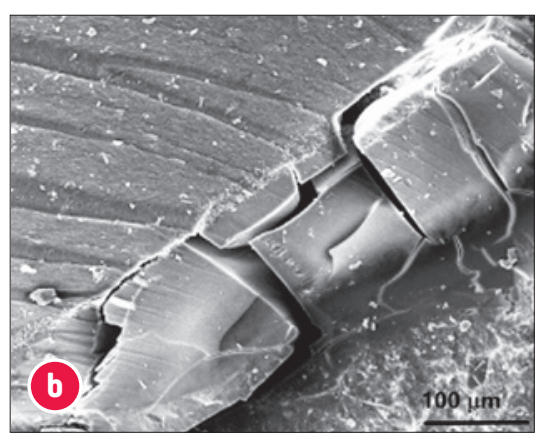

Detalhe da formação de gel maciço-gretado na zona de transição pasta-agregado

\section{Figura 7}

Imagens obtidas por microscopia eletrônica de varredura de testemunhos de concreto por ataque combinado de DEF e RAA

Fonte: Hasparyk et al. (2016)

armadura também são geradas. Características microestruturais trazem feições bastante específicas para esse tipo de manifestação patológica. Nas Figuras 8 e 9 são apresentados alguns exemplos de casos e imagens por MEV/EDS na fase de diagnóstico.

Dentre os vários casos já divulgados no exterior de estruturas de concreto afetadas pelo ataque interno por sulfatos (ISA) - originado a partir de rochas contendo minerais do tipo sulfetos - destacam-se fundações de edificações, pontes e barragens. Porém, infelizmente, no Brasil também há ocorrências nesse contexto. A quantidade de sulfetos presente pode ser variada e o nível de deterioração vai depender do tipo de sulfeto envolvido, bem como dos materiais empregados no concreto, tipo de elemento estrutural e ambiente de exposição. O que se sabe é que mesmos valores baixos (da ordem de $0,15 \%$ de sulfetos contidos no agregado) podem degradar o concreto. Não existe ainda normalização nem limite seguro em nível nacional. Alguns exemplos de sulfetos nos agregados e estrutura deteriorada podem ser visualizados nas Figuras 10 a 12 .

Já, os sulfatos que ocorrem nos agregados podem ter variadas composições, como já mencionado anterior-

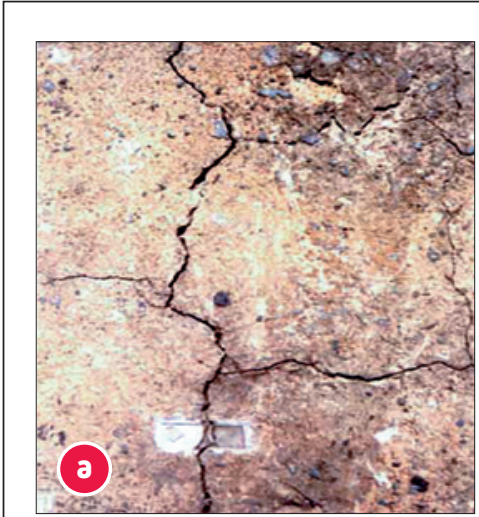

Fissuração mapeada no topo de um pilar

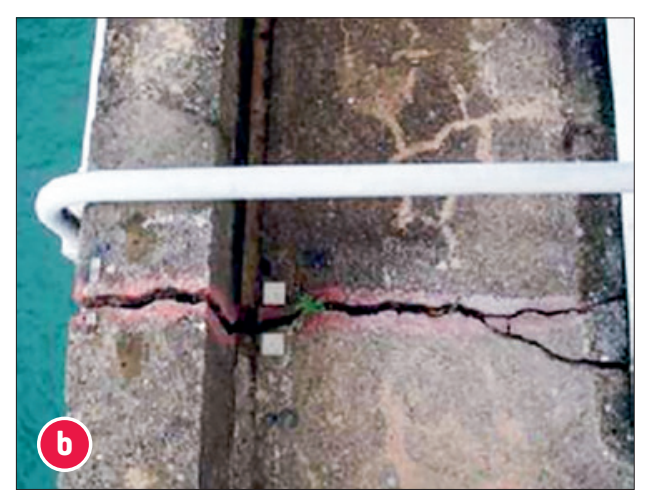

Abertura expressiva de fissura no concreto

\section{Figura 8}

Fissuração por RAA em estruturas de concreto de usinas hidrelétricas no Brasil Fonte: N. P. Hasparyk

mente, mas a maioria do meio técnico remete apenas aos sulfatos de cálcio - gipsita. Importante comentar que outras fases sulfatadas podem contaminá-los, por exemplo, os sulfatos de sódio. Na Figura 13 podem ser observadas deposições brancas em pilha de agregado britado pretendido para uso e que representavam esse tipo de contaminação por sulfatos.

\section{PRECAUÇÕES}

Para que sejam evitadas reações expansivas deletérias no concreto, uma série de cuidados são necessários. Dependendo do tipo de empreendimento, ambiente de exposição, materiais envolvidos e tipo de concreto, os protocolos podem variar um pouco.

No caso da RAA, e especificamente da RAS, variadas formas de prevenção já são conhecidas (Hasparyk, 2021). A normalização brasileira ABNT NBR 15577:2018 (Agregados - Reatividade álcali-agregado), composta de sete partes e que já se encontra referenciada na ABNT NBR 6118:2014 (Projeto de estruturas de concreto), para questões de durabilidade das estruturas de concreto, dispõe de uma série de protocolos, iniciando com uma análise de risco até métodos de ensaios apropriados tanto para investigar o potencial reativo dos agregados como para atuar preventivamente. Dentre os ensaios disponíveis para serem realizados, o método realizado em prismas de concreto é considerado o mais confiável, apesar da longa duração do ensaio, quando comparado, por exemplo, ao ensaio acelerado em barras de argamassa. Vários comportamentos de agregados e adições minerais, testadas como inibidores, podem ser observados em Hasparyk (2021).

Em relação aos ataques por sulfatos, em função das diferentes fontes, 


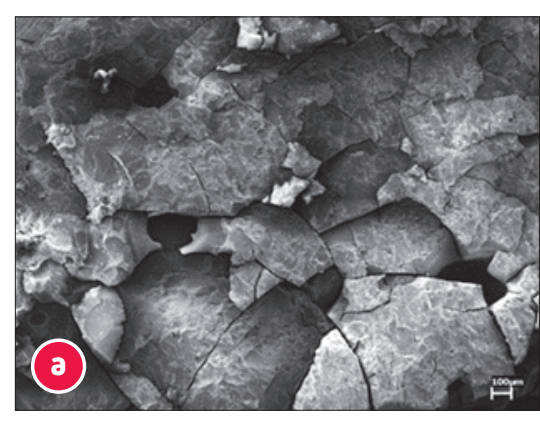

Gel maciço/gretado observado em testemunho de concreto alterado procedente de vertedouro de UHE

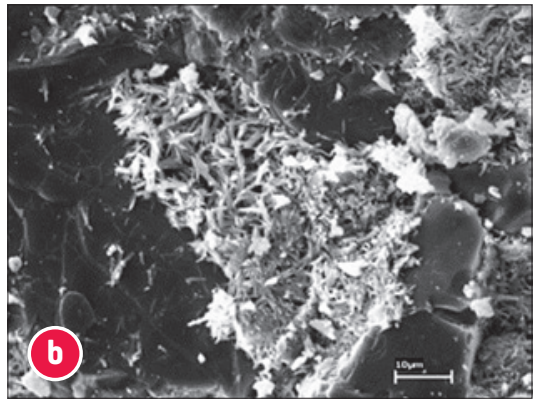

Formações cristalizadas da RAS sobre o agregado quartzito

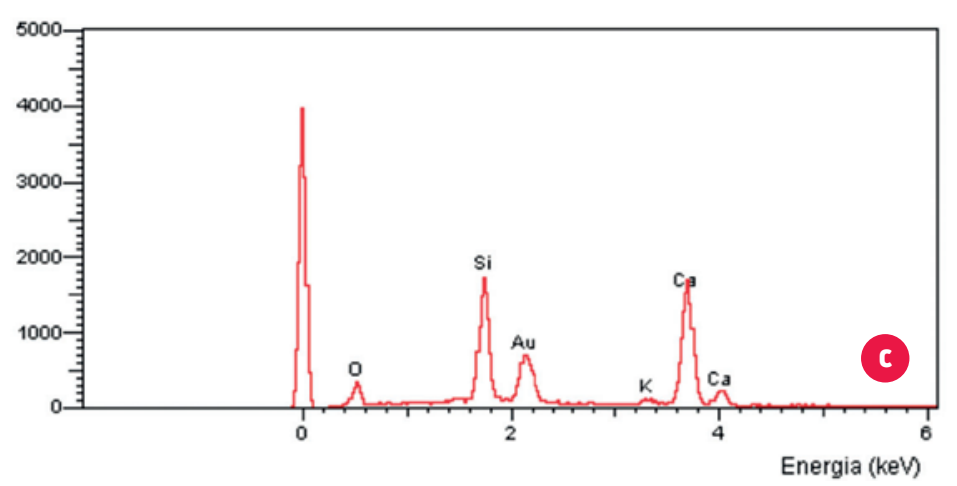

Espectro obtido por EDS do gel indicado em a)

\section{Figura 9}

Produtos da RAA - imagens obtidas no MEV/EDS

Fonte: N. P. Hasparyk

os procedimentos podem ser diferenciados. Ao se deparar com potencial exposição a um ataque externo por sulfatos, a prática mais comum adotada é o emprego de concreto de baixa permeabilidade e o uso de cimento resistente a sulfatos, melhorando-se assim a sua proteção contra o ingresso de agentes agressivos. Desta forma, é possível contornar essa situação de ataque no âmbito dos materiais e da dosagem do concreto, avaliando, em conjunto, as propriedades relacionadas. Normalmente, com o emprego de cimentos pozolânicos ou com a incorporação de adições minerais pozolânicas ao cimento é possível atingir o desejado, na presença de aditivos apropriados e limitando-se a relação água/cimento.

A ABNT NBR 12655:2015 (Concreto de cimento Portland - Preparo, controle, recebimento e aceitação) já estabelece três classes de agressividade do meio contendo sulfatos (provenientes do solo e/ou da água) no seu item 5.2.2.3. Em função da agressividade, são impostas as características preventivas necessárias para o concreto (relacionadas aos parâmetros relação água/cimento e $\left.\mathrm{f}_{\mathrm{ck}}\right)$, constituindo prática recomendável para evitar manifestações patológicas relacionadas ao ataque externo por sulfatos que poderiam comprometer a durabilidade das estruturas de concreto.

No caso de um potencial ataque interno por sulfatos, a ABNT NBR 7211:2009 (Agregados para concreto - Especificação) limita o teor de sulfatos solúveis (em água) no agregado a 0,1\%. Essa prática pode auxiliar, mas não ser suficiente uma vez que ainda existe a possibilidade da presença de outras fontes, que não o agregado.

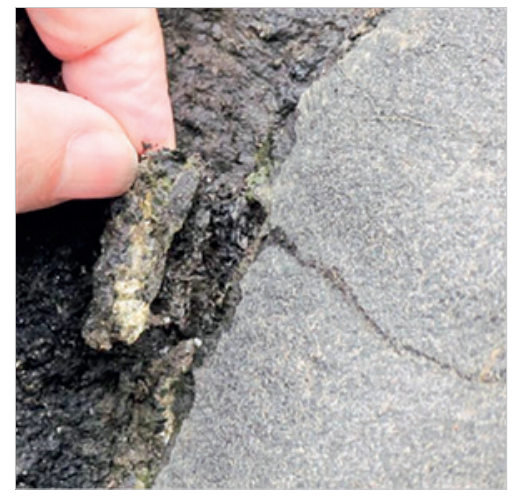

Figura 10

Sulfeto detectado em maciço rochoso

Fonte: Walton Pacelli de Andrade

Os sulfetos, ao trazerem riscos de alteração, são minerais bastante preocupantes. Já existem casos no Brasi de deteriorações decorrentes desses minerais. Ainda não há confirmação a respeito de tipos de cimento e adição adequados e que podem trazer a inibição eficiente das reações químicas envolvendo esses minerais, como já existe para a RAS. Não existe também qualquer normalização nacional, sendo assim, torna-se necessária uma análise cuidadosa dos agregados pretendidos para uso e a investigação da presença tanto de sulfatos como de sulfetos para a tomada de decisão

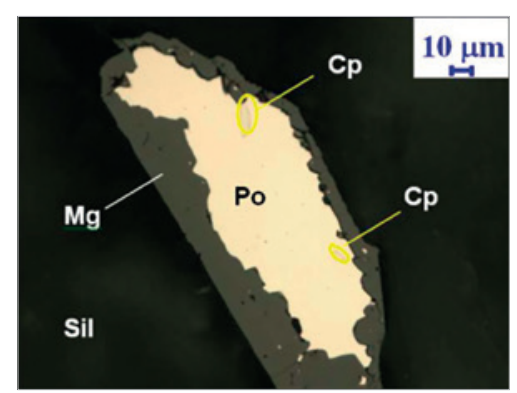

\section{Figura 11}

Cristal de pirrotita (Po) em alteração para magnetita (Mg) e inclusões de calcopirita (C $\rho)$ - agregado granítico. Imagem por microscopia ótica de luz refletida Fonte: Batista (2013) 


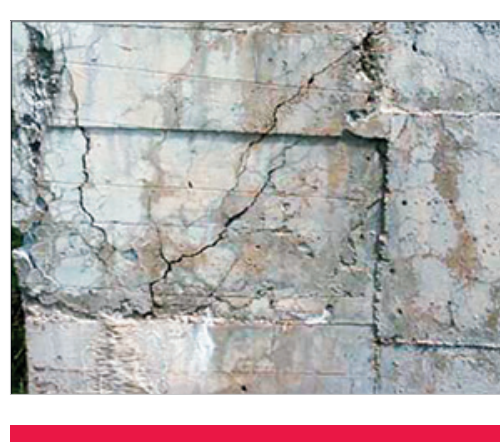

\section{- Figura 12}

Intensa fissuração na barragem de Graus (Espanha)

Fonte: Deterioração pelos sulfetos Imagem extraída de Oliveira (2011)

quanto ao seu emprego. Na sua maioria, o que se tem alertado é limitar o teor de sulfetos e, quando da presença da pirrotita, não fazer uso daquele agregado para concreto. As taxas de oxidação da pirrotita são superiores às da pirita de 20 a 100 vezes. Apesar de já ser de conhecimento dos especialistas que os sulfetos podem ser detectados por microscopia ótica de luz refletida, por meio de análises qualitativas e semiquantitativas, o único método "quantitativo" existente para avaliar a presença do elemento enxofre na forma de sulfetos e sulfatos foi publicado por FURNAS (2020), compondo uma instrução técnica - IT.GSTE005 com método de análise química.

É importante salientar que as informações a respeito dos sulfetos ainda são controversas, por isto as pesquisas precisam avançar bem como os processos de normalização.
Quanto à DEF, a prevenção em termos de limitação da temperatura a valores abaixo de $60-65^{\circ} \mathrm{C}$ é a maneira mais segura de reduzir a probabilidade de danos futuros. Tanto concretos massa (menor dimensão superior a 1 metro) como concretos estruturais devem restringir a temperatura máxima atingida, seja pela hidratação do cimento ou por cura térmica. Ainda não existe normalização nacional que trata desse assunto e o único método existente no Brasil para avaliar o potencial de desenvolvimento da DEF foi publicado por FURNAS em 2020, compondo uma instrução técnica com método de ensaio em prismas de concreto (IT.GSTE004).

Quando existem riscos do atingimento de temperaturas elevadas, procedimentos de refrigeração são necessários, podendo ser adotados pré-refrigeração e/ou pós refrigeração, como, por exemplo, uso de serpentinas, resfriamento dos materiais, emprego de gelo substituindo a água de amassamento, uso de água resfriada, entre outros. Assim, tensões térmicas e fissurações decorrentes do resfriamento do concreto, bem como a ocorrência da DEF podem ser evitados.

\section{CONSIDERAÇÕES}

Esse trabalho traz informações sobre os principais tipos de reações

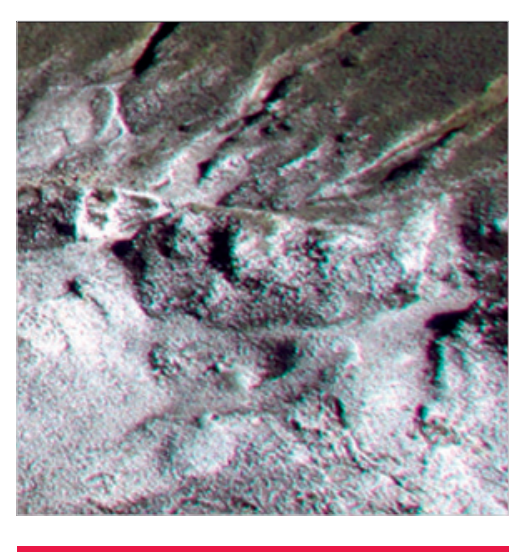

\section{Figura 13}

Pilha de agregado para concreto com deposição de sais sulfato

Fonte: N. P. Hasparyk

expansivas que podem acometer as estruturas de concreto e levá-las à deterioração. Um dos entraves existentes para a escolha de materiais adequados e que evitem as reações expansivas reside na longa duração dos ensaios. Apesar do avanço no conhecimento, ainda é necessário haver um grande empenho nos estudos sobre este tema, principalmente os dedicados a ensaios de curta duração.

É perfeitamente viável, atualmente, evitar o aparecimento dessas reações, como RAS, DEF, ISA, ESA, através de estudos adequados dos materiais e dos procedimentos construtivos previstos para cada obra.

Não é mais possível aceitar passivamente o aparecimento de estruturas de concreto, como as mencionadas neste trabalho, com deteriorações causadas por reações expansivas.

\section{DREFERÊNCIAS BIBLIOGRÁFICAS}

[1] BATISTA, D.G. Dissertação (Mestrado). Investigação da deterioração de concretos de UHEs por reações com os agregados, Programa de Pós-Graduação em Geotecnia, Estruturas e Construção Civil, UFG, Goiânia-GO. 2013.

[2] COUTO, T.A. Dissertação (Mestrado). Reação álcali-agregado: Estudo do fenômeno em rochas silicosas, Curso de Mestrado em Engenharia Civil, UFG, Goiânia-G0. 2008.

[3] FURNAS. Instrução Técnica Furnas no GSTE004RO \& GSTE005RO - Método de Ensaio para a Avaliação do Potencial de Ocorrência da Etringita Tardia (DEF) em Concreto / Método de Ensaio para a Determinação do Teor de Enxofre na Forma de Sulfetos e Sulfatos em Agregados para Concreto, Ed. Furnas, 2020.

[4] HASPARYK, N.P. Reação álcali-agregado no concreto (Capítulo 27). In: ISAIA, G. C. Concreto, Ciência e Tecnologia. São Paulo: IBRACON, 2021 (no prelo).

[5] HASPARYK, N.P.; KUPERMAN, S.; TORRES, J.R. Combined attack from AAR and DEF in the foundation blocks of a building. In. $15^{\text {th }}$ ICAAR - International Conference on Alkali-Aggregates Reaction in Concrete, Proceedings of the 15 $5^{\text {th }}$ ICAAR. São Paulo: Ed. Bernardes, H.; Hasparyk, N. P, 2016, Paper n. 106, 11p.

[6] OLIVEIRA, I. PhD Tesis. Reacción sulfática interna en presas de hormigón: cinética del comportamiento, Universidad Politécnica de Catalunya, Barcelona. 2011. 